\title{
The sequence of vessel interruption during lobectomy for non-small cell lung cancer: Is it indeed important?
}

\author{
Yael Refaely, MD \\ Siegal Sadetzki, MD, MPH ${ }^{\mathrm{b}}$ \\ Angela Chetrit, $\mathrm{MA}^{\mathrm{b}}$ \\ David A. Simansky, MDa \\ Michael Paley, MD ${ }^{\mathrm{a}}$ \\ Baruch Modan, MD, $\mathrm{DrPH}^{\mathrm{c}}$ \\ Alon Yellin, $\mathrm{MD}^{\mathrm{a}}$
} From the Department of Thoracic Surgery ${ }^{\mathrm{a}}$
and Cancer Epidemiology Unit, Gertner In-
stitute, $^{\mathrm{b}}$ Sheba Medical Center, Tel
Hashomer, Israel, and Stanley Steyer Insti-
tute for Cancer Epidemiology and Re-
search, ${ }^{\mathrm{C}}$ Tel Aviv University Medical
School, Tel Aviv, Israel.
Received for publication July 17, 2002; re-
visions requested Sept 3, 2002; revisions
received Oct 11, 2002; accepted for publi-
cation Oct 22, 2002.

Address for reprint requests: Alon Yellin, MD, Department of Thoracic Surgery, Sheba Medical Center, Tel Hashomer, Israel (E-mail: ayellin@sheba.health.gov.il).

J Thorac Cardiovasc Surg 2003;125: 1313-20

Copyright (C) 2003 by The American Association for Thoracic Surgery

0022-5223/2003\$30.00+0

doi:10.1016/S0022-5223(03)00022-9
Objective: During pulmonary resections for non-small cell lung cancer, the pulmonary vein is traditionally interrupted first to prevent seeding of malignant cells and consequently decrease metastatic implantation. This hypothesis was never confirmed scientifically. The aim of the present study was to determine whether the sequence of vessel interruption during lobectomy (lobar vein or lobar artery first) affects disease recurrence.

Methods: A historical prospective study was performed of 279 consecutive patients with complete follow-up, who survived lobectomy for non-small cell lung cancer during 1992 to 1998, in a single center. Pre-, intra-, and postoperative variables were collected from the medical records; recurrence and vital status were obtained from follow-up files, central population registry, and personal confirmation, updated to December 2000. Comparison of recurrence rates by sequence of ligation and other independent variables was assessed by univariate and multivariate logistic regression analyses.

Results: A total of 133 patients $(48 \%)$ had vein interruption before the artery (V-first) and $146(52 \%)$ had artery interruption first (A-first). The distribution of demographic, clinical, and other characteristics was similar between the 2 groups, except for the operated side and performing surgeons. The morbidity, blood requirement, and length of stay were equal for both groups. The total recurrence rate (A-first, 53\%; V-first, 51\%) was similar. Multivariate analysis (controlling for the effect of the performing surgeon) revealed elevated risk for recurrence among patients with high disease stage (odds ratio $=2.54$ ), male gender (odds ratio = 1.59), intraoperative lung manipulation (odds ratio $=2.72$ ), and blood transfusion (odds ratio $=1.49$ ). Sequence of vessel interruption was not found as a risk factor for recurrence (odds ratio $=1.29 ; 95 \% 0.73$ to $2.29, P=.4$ ).

Conclusions: Our results did not show that sequence of vessel interruption during lobectomy plays a role in tumor recurrence. A prospective study with randomization in selection of method as well as surgeons for each patient is needed to confirm these results.

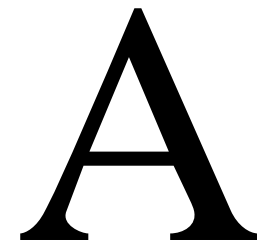

lthough many new treatment modalities have been proposed recently to improve survival of patients with non-small cell lung cancer (NSCLC), surgery and complete removal of the primary tumor and its involved lymph nodes remains the most effective treatment for these patients. ${ }^{1}$ The basic technique for lobectomy, the most common type of resection, did not change since the 1940s when individual hilar dissection evolved., ${ }^{2,3}$ During the years there were 
changing fashions regarding the sequence of vessel interruption (lobar veins first and arteries to be followed or vise versa). Today's standpoint is much more liberal and the recommendation is that the order of vessel dissection and division will be according to the surgeon's preference. ${ }^{4}$ Theoretically, manipulation of the lung during operation can produce spillage of tumor cells into the circulation and seeding of micrometastasis to distant organs. Therefore, interruption of the lobar vein before ligation of the artery may be justified. Lobar artery interruption first, on the other hand, may have an advantage in preventing unnecessary blood loss as the blood supply to the lobe is immediately closed. Several studies support vein interruption before artery. One experimental study on animals ${ }^{5}$ showed that surgical manipulation of tumors evokes enhancement of metastases. In another study, ${ }^{6}$ higher levels of tumor marker were found in the peripheral blood of patients with NSCLC who underwent lobectomy in an artery-to-vein sequence compared with those with a vein-to-artery sequence. The claim that interruption of the artery before the vein may lessen the blood loss during surgery was rejected by Miller and colleagues ${ }^{7}$ in an animal study. Practical implications on prognosis, determined by the sequence of the procedure, remain unsolved.

Interestingly, the issue whether surgical manipulation affects prognosis has gained growing attention recently since the introduction of the video-assisted (VATS) lobectomy. One of the arguments against VATS lobectomy for lung cancer is that the forceful retraction of the lung, which is necessary to achieve clear video visualization during this procedure, may increase the risk of tumor cell dissemination and therefore affect the patient's prognosis. ${ }^{8}$

The aim of the present report was to examine the possible effect of sequence of vessel interruption (lobar vein first versus lobar artery first) on prognosis in patients undergoing lobectomy for NSCLC.

\section{Materials and Methods}

From January 1992 to December 1998, 307 patients underwent lobectomy for NSCLC in the Chaim Sheba Medical center. Of these, 10 patients were excluded from this analysis due to mixed order of vessels interruption during the lobectomy, 12 patients were excluded due to perioperative death (defined as death within 30 days after surgery or at any time if the patient was never discharged from the hospital), and 6 other patients were excluded because they were lost to follow-up. These last 6 patients are all alive according to the Israeli central population registry but their disease status is unknown. Thus, 279 patients (90.9\% of the target population) were included in this study. Of them, $133(48 \%)$ underwent interruption of pulmonary vein before artery (designated "V-first") and 146 (52\%) underwent interruption of pulmonary artery first (designated "A-first"). The decision of which method to use in each operation was based on the discretion of the operating surgeon.
Demographic, preoperative, intraoperative, postoperative, and histologic data was collected by a retrospective review of the medical records. Disease status (ie, free from disease or recurrence) was updated from outpatient clinic records and telephone survey for all uncertain conditions. Vital status was updated via the Israeli's Central Population Registry.

Preoperative evaluation included smoking and medical history, previous malignancies, previous operations on the chest, laboratory tests, pulmonary function tests, and imaging evaluation. Operative data included presence of pleural adhesions, obtainment of frozen section before resection, types of lobectomy, sequence of vessel interruption, and additional resections performed during this procedure. Cases in which significant lung retraction was necessary before proceeding with lobar resection (en bloc chest wall resection before hilar dissection and management of severe adhesions) were also recorded and designated as "lung manipulation." Completeness of resection was defined as free peripheral and hilar margins and negative lymph node in the higher station sampled. Histologic data and pathologic staging according to the international lung cancer staging system ${ }^{9}$ were also recorded. For 38 patients who received preoperative treatment (mainly neoadjuvant chemotherapy) the preoperative clinicohistological stage of disease was used. Postoperative complications were categorized as medical (eg, fever, pneumonia) and technical complications (eg, air leak). Use of blood transfusion and length of hospital stay were also recorded.

All patients were followed until death, recurrence, or study termination on December 2000, whichever came first. Mean follow up was 22.6 months (range 0.16-106 months). The end point of the present study was defined as recurrence. This dependent variable was categorized in two groups: "recurrence" (considered as death from the disease or staying alive with a diagnosed disease) and "nonrecurrent" (all patients who were alive without disease or died from other illness).

\section{Statistical Analysis}

All statistical analysis was done with SAS software (SAS, Inc, Cary, NC). Statistical significance for difference between the two treatments groups ( $\mathrm{V}$-first and A-first) for each continuous variable was evaluated by means of a 1-way analysis of variance. Comparison of categorical variables between the 2 groups was performed by the $\chi$-square test or the Fisher exact test according to the cell size examined. A correlation matrix was used to examine possible association between completeness of resection and stage of disease, between performing surgeon and stage. A logistic multivariate analysis was performed to determine whether the method of surgery (sequence of vessel interruption) had an impact on recurrence of the disease, controlling for the known and significant factors for recurrence. We first estimated the risk of recurrence for sequence of interruption, introduced the stage of disease, then included performing surgeon, and investigated the interaction between sequence of interruption and performing surgeon. Finally, we entered the remaining factors that were found to be associated with recurrence in the univariate analysis: gender, lung manipulation, and blood transfusion. This step-by-step process enabled us to determine whether the effect of sequence of interruption was changed by the above-mentioned covariates. 
TABLE 1. Demographics and tumor-related variables

\begin{tabular}{|c|c|c|c|c|c|c|c|}
\hline \multirow[b]{2}{*}{ Variable } & \multicolumn{2}{|c|}{ Total } & \multicolumn{2}{|c|}{ V-first } & \multicolumn{2}{|c|}{ A-first } & \multirow[b]{2}{*}{$P$ value } \\
\hline & No & $\%$ & No & $\%$ & No & $\%$ & \\
\hline Total & 279 & 100 & 133 & 100 & 146 & 100 & \\
\hline $\begin{array}{l}\text { Age (mean } \pm S D) \\
\text { Gender }\end{array}$ & \multicolumn{2}{|c|}{$65.1 \pm 10$} & \multicolumn{2}{|c|}{$64.5 \pm 10$} & \multicolumn{2}{|c|}{$65.7 \pm 10$} & NS \\
\hline Male & 175 & 62.7 & 86 & 64.7 & 89 & 61 & NS \\
\hline Female & 104 & 37.3 & 47 & 35.3 & 57 & 39 & \\
\hline $\begin{array}{l}\text { Positive history of smoking } \\
\text { Previous malignancies* }\end{array}$ & 217 & 77.7 & 109 & 82 & 108 & 74.5 & NS \\
\hline Yes & 38 & 13.7 & 17 & 12.9 & 21 & 14.4 & NS \\
\hline No & 240 & 88.3 & 115 & 87.1 & 125 & 85.6 & \\
\hline \multicolumn{8}{|l|}{ Histology } \\
\hline Squamous cell & 83 & 29.7 & 44 & 33.1 & 39 & 26.7 & NS \\
\hline Adenocarcinomat & 151 & 54.1 & 63 & 47.4 & 88 & 60.3 & \\
\hline Large cell & 19 & 6.8 & 9 & 6.8 & 10 & 6.8 & \\
\hline Bronchoalveolar & 13 & 4.7 & 9 & 6.8 & 4 & 2.7 & \\
\hline Others & 13 & 4.7 & 8 & 6 & 5 & 3.5 & \\
\hline \multicolumn{8}{|l|}{ Grade } \\
\hline Well diff. & 58 & 20.9 & 29 & 21.8 & 29 & 19.9 & NS \\
\hline Well to mod diff. & 23 & 8.3 & 12 & 9 & 11 & 7.5 & \\
\hline Mod diff. & 62 & 22.4 & 33 & 24.8 & 29 & 19.9 & \\
\hline Mod to poor & 13 & 4.7 & 1 & 0.8 & 12 & 8.2 & \\
\hline Poorly diff. & 75 & 27.1 & 41 & 30.8 & 34 & 23.3 & \\
\hline Unknown & 48 & 17.2 & 17 & 12.8 & 31 & 21.2 & \\
\hline \multicolumn{8}{|l|}{ Stage } \\
\hline 1 & 152 & 54.5 & 77 & 57.9 & 75 & 51.4 & NS \\
\hline II & 50 & 17.9 & 21 & 15.8 & 29 & 19.9 & \\
\hline III & 68 & 24.4 & 29 & 21.8 & 39 & 26.7 & \\
\hline IV & 9 & 3.2 & 6 & 4.5 & 3 & 2.1 & \\
\hline
\end{tabular}

*Missing data for one patient from the "V-first."

†Adenocarcinoma vs. all other histological types, $P=.04$.

\section{Results}

\section{Demographic- and Tumor-Related Variables}

The mean age of the study population was $65.1( \pm 10)$ years. Male/female ratio was 1.7 (63\% men and 37\% women). There were no significant differences between the V-first group and the A-first group in respect to all demographic variables such as age, sex, and smoking history (Table 1).

No statistically significant differences were found between the groups regarding the percent of patients having $50 \%$ or more than the predicted forced expiratory volume in 1 second as well as in forced vital capacity (not shown).

Table 1 also includes tumor-related variables such as tumor type, grade, and stage. Adenocarcinoma was the most common histologic diagnosis in both groups, accounting for $54.1 \%$ of all tumors $(60.3 \%$ among the A-first group and $47.4 \%$ among the $\mathrm{V}$-first group, $P=.04$ ). Squamous cell carcinoma was the second most common tumor (29.7\%). Mixed type and unspecified NSCLC were combined in the same category and designated as "others." A large proportion of the patients were diagnosed at stage I (54.5\%), again with similarity in the 2 groups. No significant differences in the distribution of the 2 study groups by grade or by previous malignancy were observed.

\section{Operative Approach Characteristics}

As was stated before, all patients underwent lobectomy, but 66 patients $(23.7 \%)$ had additional resections in the same session such as sleeve, pericardium, wedge of lung, pleura, or diaphragm (Table 2). Ten (15\%) of them had 2 additional resections. There was no significant difference between the 2 study groups regarding the additional resections but wedge resection was significantly more prevalent in the A-first group (10.3\%) compared with the patients in the V-first group(3.8\%). Right-sided resection and hence tumor location was significantly more prevalent in the V-first group (Table 2). Complete resection was performed on $81 \%$ with no difference between the 2 study groups. There was no significant difference between the 2 study groups in obtaining frozen section before proceeding with lobar resection. Performance of lung manipulation was more common in the A-first group (10.3\% versus $4.5 \%)(P=$ $.07)$.

Strong correlation was found between the surgeon and the sequence of interruption that was used $(P<.001)$. Most of the "V first" (48.9\%) were performed by surgeon B, while most of the "A first" (56.9\%) were performed by surgeon A. The group of "other" surgeons that were desig- 
TABLE 2. Operative approach characteristics

\begin{tabular}{|c|c|c|c|c|c|c|c|}
\hline \multirow[b]{2}{*}{ Variables } & \multirow[b]{2}{*}{ No. } & \multirow[b]{2}{*}{$\%$} & \multicolumn{2}{|c|}{ V-first } & \multicolumn{2}{|c|}{ A-first } & \multirow[b]{2}{*}{$P$ value } \\
\hline & & & No. & $\%$ & No. & $\%$ & \\
\hline Total & 279 & 100 & 133 & 100 & 146 & 100 & \\
\hline \multicolumn{8}{|l|}{ Type of resection } \\
\hline \multicolumn{7}{|l|}{ Combined resection } & NS \\
\hline Sleeve & 16 & 5.7 & 11 & 8.3 & 5 & 3.4 & NS \\
\hline Pericard & 2 & 0.7 & 1 & 0.8 & 1 & 0.7 & NS \\
\hline Wedge & 20 & 7.2 & 5 & 3.8 & 15 & 10.3 & .03 \\
\hline CW, pleura, diaphragm & 38 & 13.6 & 18 & 13.5 & 20 & 13.7 & NS \\
\hline \multicolumn{8}{|l|}{ Side } \\
\hline Left & 113 & 40.6 & 45 & 34.1 & 68 & 46.6 & .03 \\
\hline Right & 165 & 59.3 & 87 & 65.9 & 78 & 53.4 & \\
\hline \multicolumn{8}{|l|}{ Complete resection } \\
\hline Yes & 226 & 81 & 107 & 80.5 & 119 & 81.5 & NS \\
\hline No & 53 & 19 & 26 & 19.5 & 27 & 18.5 & \\
\hline \multicolumn{8}{|l|}{ Frozen section } \\
\hline Yes & 61 & 21.9 & 28 & 21.1 & 33 & 22.6 & NS \\
\hline No & 218 & 78.1 & 105 & 78.9 & 113 & 77.4 & \\
\hline \multicolumn{8}{|l|}{ Lung manipulation } \\
\hline Yes & 21 & 7.5 & 6 & 4.5 & 15 & 10.3 & NS \\
\hline No & 258 & 92.5 & 127 & 95.5 & 131 & 89.7 & \\
\hline \multicolumn{8}{|l|}{ Surgeon } \\
\hline A & 105 & 37.6 & 23 & 17 & 82 & 56.9 & $<.001$ \\
\hline B & 83 & 29.7 & 66 & 48.9 & 17 & 11.8 & \\
\hline $\mathrm{C}^{*}$ & 91 & 32.6 & 46 & 34.1 & 45 & 31.3 & \\
\hline Blood transfusion & 75 & 27 & 37 & 27.8 & 38 & 26.6 & NS \\
\hline During surgery & 35 & 12.6 & 20 & 15 & 15 & 10.4 & \\
\hline Following surgery & 30 & 10.8 & 14 & 10.5 & 16 & 11.1 & \\
\hline Both & 10 & 3.6 & 3 & 2.3 & 7 & 4.9 & \\
\hline
\end{tabular}

${ }^{*}$-a group of: all other surgeons.

nated as $\mathrm{C}$ used both methods of interruption in similar rates.

Postoperative complications were present in $32 \%$ of the study population with no significant differences, technical or other, between the groups. The mean hospital stay was 9.51 days $( \pm 4.98)$ for the A-first group and 8.88 days $( \pm 4.93)$ for the V-first group. This also was without significant difference between the groups.

\section{Follow-up and Recurrence}

Total disease recurrence rate was $52.3 \%, 78$ patients (53\%) of the A-first group and 68 patients $(51 \%)$ of the V-first group $(P=.7)$.

Risk factors for recurrence of disease (Table 3) were: male sex $(P=.01)$, high stage of disease $(P<.0001)$, incomplete resection $(P<.0001)$, blood transfusion $(P=$ $.006)$, and lung manipulation $(P=.006)$.

Significant association was found between stage of disease and performance of complete resection; although 93\% of patients in stages I to II underwent complete resection, this was achieved in only about $50 \%$ of patients in higher stages $(P<.0001)$. Therefore, these 2 parameters could not be included in the same model.
Table 4 presents 4 separate models of analysis, where the variable under investigation was retained in the models, and the other variables that emerged as significant in the univariate analysis were entered gradually. Stage of disease showed about threefold increased risk for recurrence, which remained similar after introducing the influence of the performing surgeon (models 2 and 3). Because the distribution of sequence of interruption was significantly different between surgeons, and to rule out possible confounding and/or modifying effect, we investigated the main effect of surgeon and its interaction with sequence of interruption. The $P$ value for the overall effect of surgeon was .09 and the interaction was not significant $(P=.2$; not shown).

The fourth model showed elevated risk for recurrence among patients with high stage of disease (odds ratio [OR] $=2.54,95 \%$ confidence intervals $[\mathrm{CI}]$ 1.39-4.65), male gender $(\mathrm{OR}=1.59,95 \%$ CI $0.95-2.67)$, patients who underwent lung manipulation $(\mathrm{OR}=2.72,95 \% \mathrm{CI} 0.84-8.81$ ), and patients who received blood transfusion $(\mathrm{OR}=1.49$, 95\% CI 0.82-2.73). None of the models demonstrates evidence that sequence of interruption affected disease recurrence (from $\mathrm{OR}=1.04, P=.9$, to $\mathrm{OR}=1.29, P=.4$ in models 1 and 4 , respectively). 
TABLE 3. Univariate analysis for disease recurrence

\begin{tabular}{|c|c|c|c|c|c|}
\hline \multirow[b]{2}{*}{ Parameters } & \multirow[b]{2}{*}{ Categories } & \multirow[b]{2}{*}{ Total } & \multicolumn{2}{|c|}{$\begin{array}{l}\text { Disease recurrence } \\
\quad(N=146)\end{array}$} & \multirow[b]{2}{*}{$P$ value } \\
\hline & & & No. & $\%$ & \\
\hline \multirow[t]{2}{*}{ Gender } & female & 104 & 44 & 42.3 & \\
\hline & male & 175 & 102 & 58.3 & .01 \\
\hline Age (years) & $<70$ & 177 & 90 & 50.8 & \\
\hline \multirow{2}{*}{ Pathology } & ACOBAC & 151 & 79 & 52.3 & \\
\hline & others & 45 & 20 & 44.4 & NS \\
\hline \multirow[t]{4}{*}{ Stage } & I & 152 & 62 & 40.8 & \\
\hline & II & 50 & 28 & 56.0 & \\
\hline & III & 68 & 49 & 72.1 & \\
\hline & IV & 9 & 7 & 77.8 & $<.0001$ \\
\hline \multirow[t]{2}{*}{ Side* } & left & 113 & 60 & 53.1 & \\
\hline & right & 165 & 86 & 52.1 & NS \\
\hline \multirow[t]{2}{*}{ Blood transfusion } & no & 202 & 95 & 47.0 & \\
\hline & yes & 77 & 51 & 66.2 & .006 \\
\hline \multirow[t]{2}{*}{ Previous malignancies* } & no & 240 & 127 & 52.9 & \\
\hline & yes & 38 & 19 & 50.0 & NS \\
\hline \multirow[t]{2}{*}{ Frozen section } & no & 218 & 119 & 54.6 & \\
\hline & yes & 61 & 27 & 44.3 & NS \\
\hline \multirow[t]{2}{*}{ Lung manipulation } & no & 258 & 129 & 50.0 & \\
\hline & yes & 21 & 17 & 81.0 & .006 \\
\hline
\end{tabular}

ACOBAC, Adenocarcinoma other than bronchoalveolar type.

${ }^{*}$ One subject with missing information.

TABLE 4. Multivariate logistic models results for factors influencing recurrence of disease

\begin{tabular}{|c|c|c|c|c|c|c|c|c|c|c|c|c|c|}
\hline \multirow[b]{2}{*}{ Variables } & \multirow[b]{2}{*}{ Categories } & \multicolumn{3}{|c|}{ I } & \multicolumn{3}{|c|}{ II } & \multicolumn{3}{|c|}{ III } & \multicolumn{3}{|c|}{ IV } \\
\hline & & CR & $95 \% \mathrm{Cl}$ & $\boldsymbol{P}$ & OR & $95 \% \mathrm{Cl}$ & $P$ & OR & $95 \% \mathrm{Cl}$ & $P$ & OR & $95 \% \mathrm{Cl}$ & $\boldsymbol{P}$ \\
\hline Sequence interruption & A vs. V & 1.04 & $0.65-1.66$ & .9 & 1.02 & $0.63-1.66$ & .9 & 1.32 & $0.75-2.32$ & .3 & 1.29 & $0.73-2.29$ & .4 \\
\hline Stage & III-IV vs. I-II & & & & 3.32 & $1.87-5.89$ & .001 & 3.06 & $1.71-5.47$ & .001 & 2.54 & $1.39-4.65$ & .003 \\
\hline Surgeon & Overall effect & & & & & & & & & .09 & & & .13 \\
\hline Lung manipulation & Yes vs. No & & & & & & & & & & 2.72 & $0.84-8.81$ & .1 \\
\hline Blood transfusion & Yes vs. No & & & & & & & & & & 1.49 & $0.82-2.73$ & .2 \\
\hline Gender & M vs. F & & & & & & & & & & 1.59 & $0.95-2.67$ & .08 \\
\hline
\end{tabular}

The same analyses were performed while replacing stage of disease by completeness of resection due to the association observed between these two variables. Sequence of interruption remained uninfluential in accordance with the findings reported in Table 4.

\section{Discussion}

Although the assumption that certain manipulations on the lung during resection for malignancy causing shedding of tumor cells into the blood stream may eventually cause metastasis and adversely affect the prognosis makes sense, it has never been proven by clinical evidence. Moreover, the sequence of vessel interruption during lobectomy for NSCLC as an independent prognostic variable was never examined in an epidemiologic study.

Our main aim in this study was to evaluate the impact that the sequence of hilar vessel interruption during lobectomy for NSCLC has on prognosis. Our results did not confirm that the sequence of interruption (artery first versus vein first) is a risk factor for disease recurrence $(\mathrm{OR}=1.29$, 95\% CI 0.73-2.29). The report by Kurusu and associates ${ }^{6}$ is the only previous study in the literature that evaluated the sequence of vessel ligation during lobectomy for NSCLC as an independent variable for outcome, and indeed found that 
it is a predictor for tumor cell spread in the circulation. They examined the presence of a peripheral epithelial marker (carcinoembryotic antigen messenger ribonucleic acid) in the circulation before, during, and after lobectomy in 30 patients with NSCLC. Each patient was randomly assigned to have either lobar vein interruption or lobar artery interruption first. Nine of the 14 patients with preoperative negative test results became positive during the operation. Such conversion was more common with arterial interruption first than with vein interruption first $(6 / 7$ versus $3 / 7$ patients). They concluded that ligation of the pulmonary vein before ligating the artery may lessen intraoperative hematogenous dissemination. In another similar study by this group, ${ }^{8}$ using the same peripheral marker, VATS lobectomy was compared with open lobectomy. The authors found that VATS lobectomy was associated with a higher risk of seeding of tumor cells into the circulation during operation. This phenomenon was suggested to be related to a more frequent and forceful retraction and manipulation of the diseased lobe to attain better fields of vision during VATS lobectomy. However, no survival or recurrence rate data were available for the patients in both studies. The presence of circulating tumor cells is an indirect parameter for metastatic spread and does not necessarily predict the subsequent appearance of clinical metastatic disease. The clinical significance of the findings in these 2 studies remains unclear.

Although the main goal of the present study was to determine the significance of the sequence of vessel interruption, we evaluated multiple factors. In most multivariate analyses for operated patients, stage of disease and performance status were found to be the most important prognostic factors for survival. ${ }^{1,10-12}$ In our study, stage of disease emerged as the strongest risk factor for disease recurrence $(\mathrm{OR}=2.54,95 \%$ CI 1.39-4.65). Because performance status was not specified in all charts it was not included as a variable in our model. Incomplete resection highly correlated with stage in our analysis and was found to be strong prognostic risk factor for recurrence. The prognosis and management of an incompletely resected NSCLC is somewhat disputed in the current surgical literature, resulting mainly from differences in terminology. Traditionally, macroscopic or microscopic residual disease at the resection margin has been designated as incomplete resection, but many investigators include also the presence of tumor in the highest mediastinal node sampled. ${ }^{13}$ Lacasse and colleagues ${ }^{14}$ studied incomplete resection in NSCLC using the broader definition in a logistic regression model for disease recurrence or death, and did not find it to be a prognosticator.

Other risk factors that showed borderline significant evidence in this study for disease recurrence were: male gen$\operatorname{der}(P=.08)$ and lung manipulation $(P=.1)$. The per- forming surgeon had some influence although with borderline significance $(P=.13)$. Our finding of a lower risk for recurrence among women is in accordance with the literature, where female sex was associated with significantly longer survival ${ }^{15}$ and event-free survival. ${ }^{16}$

Blood transfusion also showed excess risk for recurrence $(\mathrm{OR}=1.49,95 \% \mathrm{CI} 0.82-2.73)$. This issue was discussed in previous reports and a dispute exists about the impact of perioperative blood transfusion on patient prognosis. ${ }^{17-19}$ Our finding with regard to the nil effect of a previous malignancy on the outcome is in accordance with other studies. ${ }^{20-22}$

The inclusion of frozen section and lung manipulation in our analysis mandates explanation. We believe that while waiting for the frozen section result, the surgeon might have continued with hilar dissection and fissure division. In this case the sequence of interruption would not considerably affect tumor dissemination as it could have occurred before the vessels were addressed. This variable was similarly distributed between the 2 study groups and also did not affect recurrence rate. Inclusion of lung manipulation in the analysis had a similar rationale, as manipulations and forceful retraction of the lung prior to vessel interruption could cause more tumor cell dissemination than the lobectomy itself. Our results confirmed that lung manipulation is a risk factor for recurrence.

Three operative variables analyzed in the current study (ie, lung manipulation, interruption of the pulmonay artery first, and frozen section examination) share a common feature (ie, the increased risk of disseminating tumor cells into the circulation). The first 2 were proven by clinical or laboratory studies as discussed earlier ${ }^{5,6}$ to increase the presence of malignant cells in peripheral blood. Whether this phenomenon also increases the hazard for metastatic spread is yet to be determined. The process of metastatic formation depends on a myriad of host, tumor, and tumorhost relationship factors. Malignant cells are constantly shed from primary tumors into the blood stream. The majority of them are consumed by circulating macrophages ${ }^{23}$ and only a minority would complete the sequence of events required to cross the endothelium. Most of the later are destroyed by tissue defense mechanisms. Only 1:10,000 circulating malignant cells eventually creates a metastasis. ${ }^{23}$ Increased shedding of tumor cells into the circulation was demonstrated in breast cancer during surgery, ${ }^{24}$ fine needle aspiration biopsy, ${ }^{25}$ resection of hepatic metastases of colorectal carcinoma, ${ }^{26}$ and brachytherapy for prostatic cancer. ${ }^{27}$ Hayashi and colleagues ${ }^{28}$ showed that no-touch isolation techniques may lower shedding of malignant cells into the portal vein during colorectal resection. Unfortunately, none of these studies sought prognostic correlations. Thus, similar to NSCLC, the clinical importance of tumor cell dissemination during various manipulation is still a 
puzzle. Resembling but not identical to vascular dissemination is the phenomenon of a positive pleural lavage cytology in patients undergoing resection for NSCLC and presenting without pleural spread. Some investigators ${ }^{29,30}$ have shown that this is associated with a poor prognosis. In our retrospective study we have shown that lung manipulation is associated with a worse outcome, although interruption of the pulmonary artery first and frozen section are not. The impact of tumor manipulation (including sequence of interruption and use of frozen section) during surgery on recurrence could be determined by a prospective study combining clinical variables and the detection of circulating tumor cells.

The role of the operating surgeon on recurrence is one of the limitations of this study. Evidently, each surgeon is bound to his own method so that the sequence of interruption is highly associated with the surgeon performing the operation. We have tried to cope with this issue by including the effect of the operating surgeon in the multivariable analysis. The overall effect of the surgeon was with borderline significance and the interaction did not seem to alter the results. Interestingly, a review of the literature revealed that the majority of the studies that involve surgical therapy ignore the performer, the surgeon, as a possible prognostic factor for recurrence or survival. This subject was extensively discussed by Fielding and colleagues, ${ }^{31}$ who studied surgical treatment in colorectal cancer and found a wide range of postoperative mortality rates among 28 different surgeons. Our findings supported their claim that surgeons vary in the ability to produce a given result, a phenomena known as "surgeon related variability." To overcome this problem, they suggested listing the predictive variables that are "surgeon- related" and treating them in the same way that "patient-related" variables are being treated. In this way a similarity in the study groups can be achieved or, when stratification is not possible, to demonstrate when the results are reported that randomization has succeeded in equally distributing the variables. Unfortunately, these principles cannot be fully applied by and large in a retrospective study and indeed "surgeon-related" variables are hardly evident in recent studies of any type in respect to prognosis, recurrence, or survival in lung cancer. In addition, although in multicentric clinical trials the large scale of surgeons participating in the study increases the variance and the severity of this problem, it is evident that the small number of surgeons who participated in our study contributed to the presented problem. Because each surgeon was bound to his own method, only a prospective study with randomized selection of the method for each patient and defining the "surgeon-related" predictive variables can provide definite answer to this puzzling issue.

Our results do not support the hypothesis that the sequence of vessel interruption during lobectomy for NSCLC affects disease recurrence. A prospective study with randomized selection of method for each patient is needed to confirm these results.

\section{References}

1. Van Rens MT, De la Riviere AB, Elbers HR, van Den Bosch JM. Prognostic assessment of 2,361 patients who underwent pulmonary resection for non small cell lung cancer, stage I, II, and IIIA. Chest. 2000;117:374-9

2. Faber LP. Individual interruption technique for lower lobe lobectomy. Ann Thorac Surg. 1990;49:1016-8.

3. Grismer JT, Read RC. Evolution of pulmonary resection techniques and review of the bronchus-first method. Ann Thorac Surg. 1995;60: 1133-7.

4. Kaiser LR. Pulmonary resection-anatomy and techniques. In: Baue AE, Geha AS, Hammond GL, Laks H, Keith S, editors. Glenns' thoracic and cardiovascular surgery. Vol. I, 6th ed. Stamford [CT]: Appleton \& Lange; 1996. p. 117-29.

5. Nishizaki T, Matsumata T, Kanematsu T, Yasunaga C, Sugimachi K. Surgical manipulation of VX2 carcinoma in the rabbit liver evokes enhancement of metastasis. J Surg Res. 1990;49:92-7.

6. Kurusu Y, Yamashita J, Hayashi N, Mita S, Fujino N, Ogawa M. The sequence of vessel interruption affects tumor release into the circulation. J Thorac Cardiovasc Surg. 1998;116:107-13.

7. Miller GE Jr, Aberg TH, Gerbode F. Effect of pulmonary vein interruption on pulmonary artery flow in dogs. J Thorac Cardiovasc Surg. 1968;55:668-71.

8. Yamashita JI, Kurusu Y, Fujino N, Saisyoji T, Ogawa M. Detection of circulating tumor cells in patients with non-small cell lung cancer undergoing lobectomy by video-assisted thoracic surgery: a potential hazard for intraoperative hematogenous tumor cell dissemination. J Thorac Cardiovasc Surg. 2000;119:899-905.

9. Mountain CF. Revisions in the International System for Staging Lung Cancer. Chest. 1997;111:1710-7.

10. Gail MH, Eagan RT, Feld R, et al. Prognostic factors in patients with resected stage I non-small cell lung cancer. A report from the Lung Cancer Study Group. Cancer. 1984;54:1802-13.

11. Williams DE, Pairolero PC, Davis CS, et al. Survival of patients surgically treated for stage I lung cancer. J Thorac Cardiovasc Surg. 1981;82:70-6.

12. Charloux A, Hedelin G, Dietemann A, Ifoundza T, Roeslin N, Pauli G, Quoix E. Prognostic value of histology in patients with non-small cell lung cancer. Lung Cancer. 1997;17:123-34.

13. Sadeghi A, Payne D, Rubinstein L, Lad T. Combined modality treatment for resected advanced non-small cell lung cancer: local control and local recurrence. Int J Radiat Oncol Biol Phys. 1988;15:89-97.

14. Lacasse Y, Bucher HC, Wong E, Griffith L, Walter S, Ginsberg RJ, Guyatt GH. "Incomplete resection" in non-small cell lung cancer: need for a new definition. Canadian Lung Oncology Group. Ann Thorac Surg. 1998;65:220-6.

15. Albain KS, Crowley JJ, LeBlanc M, Livingston RB. Survival determinants in extensive-stage non-small-cell lung cancer: the Southwest Oncology Group experience. J Clin Oncol. 1991;9:1618-26.

16. Jazieh AR, Hussain M, Howington JA, et al. Prognostic factors in patients with surgically resected stages I and II non-small cell lung cancer. Ann Thorac Surg. 2000;70:1168-71.

17. Tartter PI, Burrows L, Kirschner P. Perioperative blood transfusion adversely affects prognosis after resection of stage I (subset N0) non-oat cell lung cancer. J Thorac Cardiovasc Surg. 1984;88:659-62.

18. Little AG, Wu HS, Ferguson MK, Ho CH, Bowers VD, Segalin A, Staszek VM. Perioperative blood transfusion adversely affects prognosis of patients with stage I non-small-cell lung cancer. Am J Surg. 1990;160:630-2 (discussion 633).

19. Pastorino U, Valente M, Cataldo I, Lequaglie C, Ravasi G. Perioperative blood transfusion and prognosis of resected stage Ia lung cancer. Eur J Cancer Clin Oncol. 1986;22:1375-8.

20. Utsumi T, Fujii Y, Takeda S, et al. Clinical study on lung cancer as a second primary cancer. Surg Today. 1998;28:487-91. 
21. Ishida T, Saitoh G, Maruyama R, et al. Survival following resection for lung cancer as a second primary cancer. Int Surg. 1995;80:227-30.

22. Koppe MJ, Zoetmulder FA, van Zandwijk N, Hart AA, Baas P, Rutgers EJ. The prognostic significance of a previous malignancy in operable non-small cell lung cancer. Lung Cancer. 2001;32:47-53.

23. Weiss L, Orr FW, Honn KV. Interactions of cancer cells with the microvasculature during metastasis. FASEB J. 1988;2:12-21.

24. Choy A, McCulloch P. Induction of tumor cell shedding into effluent venous blood in breast cancer surgery. Br J Surg. 1996;73:79-82.

25. Hu XC, Chow LWC. Fine needle aspiration may shed breast cells into peripheral blood as determined by RT-PCR. Oncology. 2000;59:21722.

26. Weitz J, Koch M, Kienle P, et al. Detection of hematogenic tumor cells in patients undergoing resection of liver metastases of colorectal cancer. Ann Surg. 2000;232:66-72.
27. Siddiqua A, Chendil D, Rowland R, et al. Increased expression of PSA mRNA during brachytherapy in peripheral blood of patients with prostate cancer. Urology. 2002;60:270-5.

28. Hayashi N, Egami H, Kai M, Kurusu Y, Takano S, Ogawa M. No-touch isolation technique reduces intraoperative shedding of tumor cells into the peripheral vein during resection of colorectal cancer. Surgery. 1999;125:369-74.

29. Okumura M, Ohshima S, Kotake Y, Morino H, Kikui M, Yasumitsu T. Intraoperative pleural lavage cytology in lung cancer patients. Ann Thorac Surg. 1991;51:599-604.

30. Kondo H, Asamura H, Suemasu K, et al. Prognostic significance of pleural lavage cytology immediately after thoracotomy in patients with lung cancer. J Thorac Cardiovasc Surg. 1993;106:1092-7.

31. Fielding LP, Stewart-Brown S, Dudley HAF. Surgeon related variables and the clinical trial. Lancet. 1978;7:778-9.

\section{Bound volumes available to subscribers}

Bound volumes of The Journal of Thoracic and Cardiovascular Surgery are available to subscribers (only) for the 2003 issues from the Publisher, at a cost of $\$ 134.00$ for domestic, $\$ 165.85$ for Canadian, and $\$ 155.00$ for international subscribers for Vol 125 (January-June) and Vol 126 (July-December). Shipping charges are included. Each bound volume contains a subject and author index and all advertising is removed. The binding is durable buckram with the Journal name, volume number, and year stamped in gold on the spine. Payment must accompany all orders. Contact Mosby, Subscription Customer Service, 6277 Sea Harbor Dr, Orlando, FL 32887, USA; phone 800-654-2452 or 407-345-4000.

Subscriptions must be in force to qualify. Bound volumes are not available in place of a regular Journal subscription. 